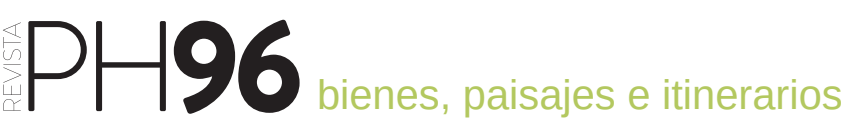

\section{Huelva y costa occidental en el IAPH}

Huelva y la costa occidental es una demarcación paisajística que se localiza en el suroeste de Andalucía. Los municipios que comprende esta demarcación son Ayamonte, Isla Cristina, Lepe, Cartaya, Aljaraque, Gibraleón, Huelva, San Juan del Puerto, Moguer, Palos de la Frontera y Punta Umbría.

A través de la Guía Digital del Patrimonio Cultural de Andalucía (https://guiadigital.iaph.es/inicio), se podrá encontrar la información de patrimonio mueble, inmueble, inmaterial y paisajes culturales, además de otros contenidos como rutas culturales, imágenes, referencias bibliográficas, productos multimedia y obras restauradas de esta demarcación.

URL de la contribución <www.iaph.es/revistaph/index.php/revistaph/article/view/4349>

\section{Patrimonio inmueble}

En la Guía Digital del Patrimonio Cultural se encuentra la información referida a un total de 809 inmuebles de esta demarcación, de los cuales el $48 \%$ corresponden al patrimonio arqueológico, el $42 \%$ al arquitectónico y el $9 \%$ al etnológico.

\section{Patrimonio mueble}

En la mencionada guía se puede consultar la información referida a 796 objetos muebles de carácter artístico en la costa occidental de Huelva distribuidos en diez municipios. Algunos de estos bienes pertenecen al Inventario de Bienes Muebles de la Iglesia Católica; otros

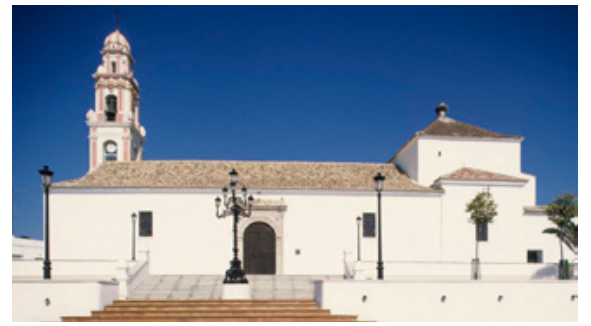

Iglesia de Nuestro Señor y Salvador.en Ayamonte foto Fondo Gráfico IAPH (Javier Romero García) a la obra escultórica de Antonio León Ortega en la provincia de Huelva, que se encuentran inscritos como bienes de catalogación general de manera colectiva en el Catálogo General del Patrimonio Histórico de Andalucía.

\section{Patrimonio inmaterial}

Respecto a los bienes de patrimonio inmaterial que podemos consultar, encontramos un total de 24 registros, de los cuales diez corresponde al ámbito de rituales festivos, otros diez al de oficios y saberes, dos a modos de expresión y otros dos de alimentación.

Las actividades relacionadas con el mar son las que tienen una mayor presencia entre los registros existentes, así como actividades estrechamente relacionadas con estos trabajos. La venta de pescado en Ionja, las salinas, la recogida de coquinas o la elaboración de guiso marinero, son algunos ejemplos de esto. Respecto a los rituales festivos, podemos encontrar ejemplos como la

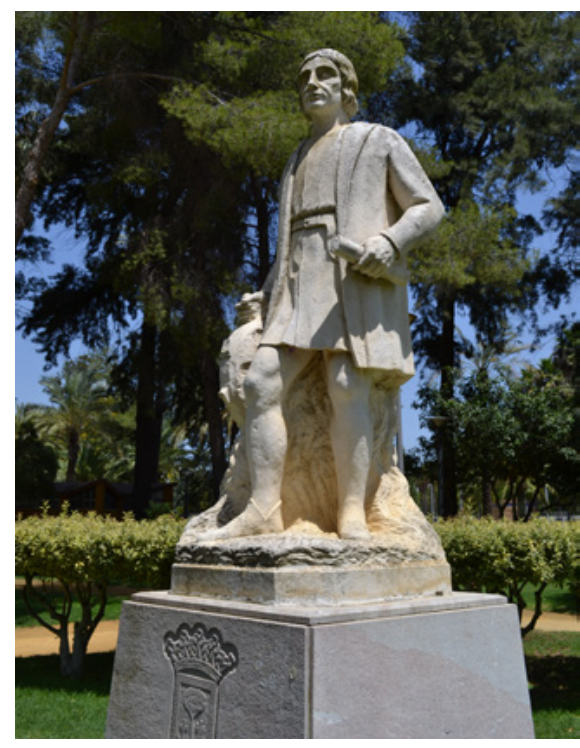

Monumento a Alonso Sánchez (Antonio León Ortega, 1970) en Huelva | foto Fondo Gráfico IAPH (Juan Antonio Arenillas Torrejón)

Semana Santa de Cartaya, la romería de la Virgen Bella o los carnavales.

\section{Paisajes culturales}

Al suroeste de la provincia de Huelva, entre el sur del Andévalo y la costa, se extiende un territorio llano poblado de pinares y ocupado con plantaciones de cítricos y culti- 
vos intensivos de invernadero en el que se ha delimitado la demarcación paisajística de Huelva y costa occidental.

En este espacio, la mayor parte de los asentamientos se concentran al oeste, en el entorno de la capital, y al noreste, en el eje GibraleónAyamonte, cercano al Algarbe portugués. Entre estas dos zonas, un vasto espacio avanza hasta el mar convirtiéndose en amplias marismas, mayoritariamente concentradas en las desembocaduras de los ríos Odiel y Tinto, en las proximidades de la capital; del río Piedras, bajando entre Lepe y Cartaya hasta El Rompido y El Portil; y en los esteros del Guadiana, cercanos a Isla Cristina y Ayamonte. Esta demar-

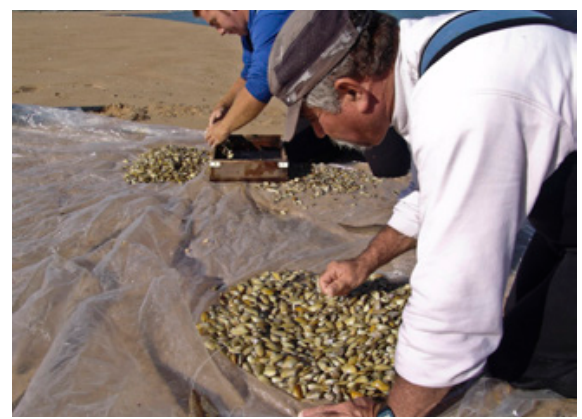

Marisqueo a pie en Cartaya | foto Fondo Gráfico IAPH (Alberto Granados Román)

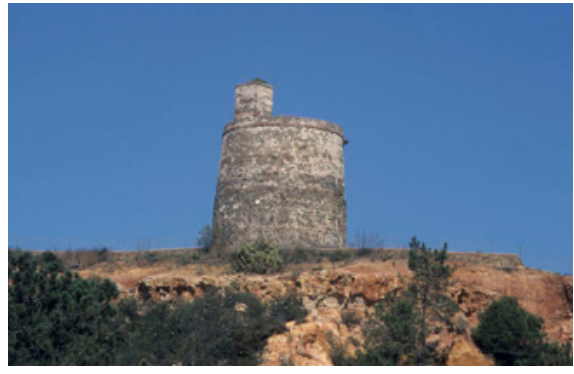

Torre del Catalán en Lepe | foto Fondo Gráfico IAPH (Javier Romero García) cación conserva un medio de gran singularidad paisajística y valor medioambiental que conecta con las playas alineadas en la práctica totalidad de la costa, entre la desembocadura del Guadiana, en la frontera con Portugal, y el término de la localidad de Mazagón, donde contactan con el entorno del Parque Nacional de Doñana.

En esta demarcación paisajística de Huelva y costa occidental ha quedado identificado el siguiente paisaje de interés cultural de Andalucía: paisaje pesquero de Isla Cristina.

\section{Rutas culturales}

En la guía digital hay una ruta cultural de la cual una parte se encuadran en la zona que estudiamos: La arquitec- tura defensiva en la costa andaluza, que constituye un rico patrimonio inmueble íntimamente ligado a los núcleos de población, que en ocasiones nacen a su amparo, y en otras, por su existencia previa, justifican la construcción de estas tipologías arquitectónicas.

Las diversas disputas que existían entre Castilla y Portugal propiciaron que en Huelva desde la Baja Edad Media se realizaran multitud de esfuerzos para la creación de espacios defensivos costeros.

\section{Bibliografía}

En cuanto a la bibliografía, podemos encontrar en el repositorio de activos digitales un total de 895 referencias bibliográficas sobre la costa occi-

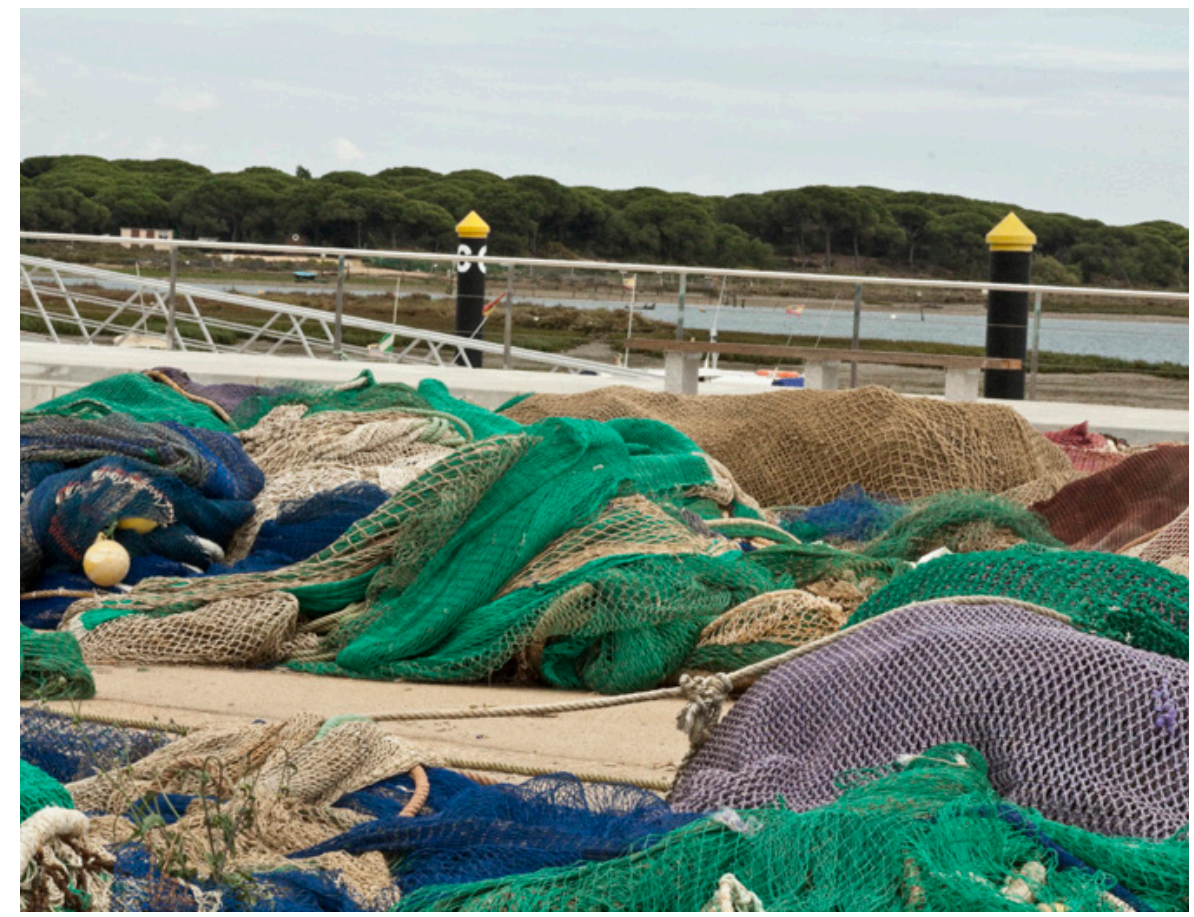

Confección de redes de pesca en Punta Umbría (Huelva) | foto Fondo Gráfico IAPH (María del Rosario Ortiz Amores) 
dental de Huelva. El municipio que posee mayor cantidad de referencias es Huelva (535), seguido de Palos de la Frontera (75) y Moguer (65).

\section{Cartografía}

Se encuentran georreferenciados en la zona un total de 320 inmuebles, 104 son puntuales y 216 poligonales, algunos de los cuales pueden consultarse a través del localizador cartográfico del patrimonio cultural.

\section{OBRAS RESTAURADAS}

\section{Materiales arqueológicos de la} necrópolis de La Joya

La necrópolis de La Joya, ubicada en el cabezo del mismo nombre en la ciudad de Huelva, constituye uno de los referentes fundamentales sobre el mundo funerario del periodo orientalizante en la Península Ibérica, no sólo por la riqueza y calidad de los ajuares en ella localizados, sino también por la diversidad en los rituales y tipologías de las estructuras funerarias documentadas.

Según se desprende del estudio de los materiales, su cronología puede establecerse desde la segunda mitad del siglo VIII a. de C. hasta la primera mitad del siglo VI a. de C., presentando un margen temporal de uso de unos dos siglos aproximadamente. La riqueza tecnológica y artística de algunas piezas del ajuar funerario, en su mayoría fabricados en bronce, halladas en las distintas campañas de excavación, y su delicado estado de conservación, impulsaron la ejecución de un proyecto para el estudio, conservación y museali- zación de los materiales depositados en el Museo de Huelva. De esta forma, se inició la restauración-conservación de una parte de los mismos en las dependencias del IAPH en 2006. La vasta información obtenida durante su desarrollo demuestra la importancia de esta necrópolis y sus amplias posibilidades de estudio. Por esta razón, en el año 2010 se desarrolló como proyecto de I+D. Poniendo de manifiesto que, a pesar de ser un yacimiento referente en la Protohistoria peninsular, aún existen numerosos interrogantes que las nuevas investigaciones deberán desvelar.

\section{Crucificado del Cementerio}

El Cristo del Cementerio es una de las imágenes de Jesús Crucificado más antigua de la provincia de Huelva por ello sorprende la escasa información que se conoce sobre su origen e historia existiendo varias hipótesis al respecto. Fue estudiada y posteriormente intervenida en el Instituto Andaluz del Patrimonio Histórico durante los años 2009 y 2010. Dicha actuación daba respuesta a la petición realizada por el Ayuntamiento de la localidad onubense de Gibraleón, propietario de la obra.

Es una escultura de madera de álamo tallada y policromada cuya ejecución se puede encuadrar entre finales del siglo XIV y principios del $\mathrm{XV}$, habiendo sido objeto de algunas intervenciones posteriores derivadas de su continua readaptación a nuevos contextos y/o usos.

Posee un notable interés histórico-artístico además de un signifi-

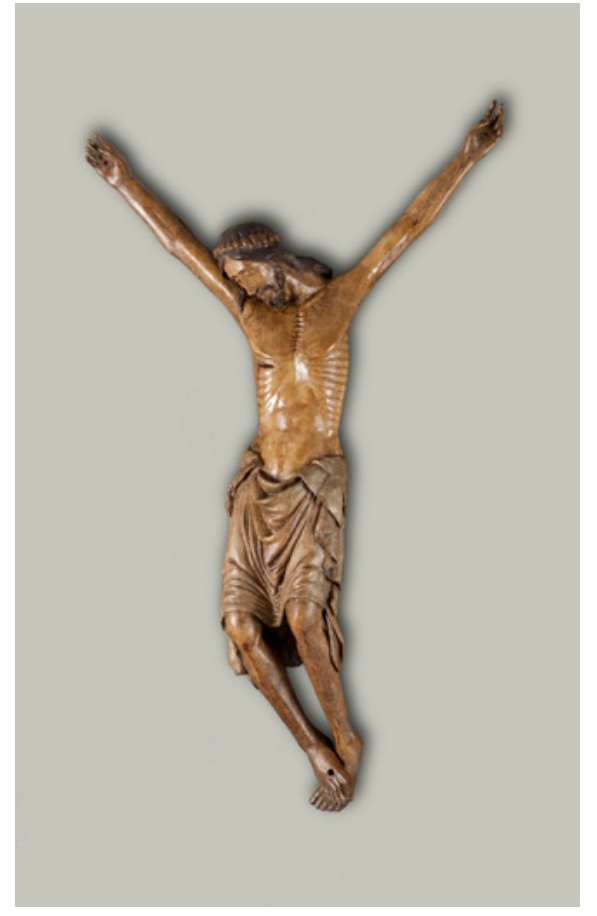

Crucificado del Cementerio de Gibraleón | foto Fondo Gráfico IAPH (Eugenio Fernández Ruiz)
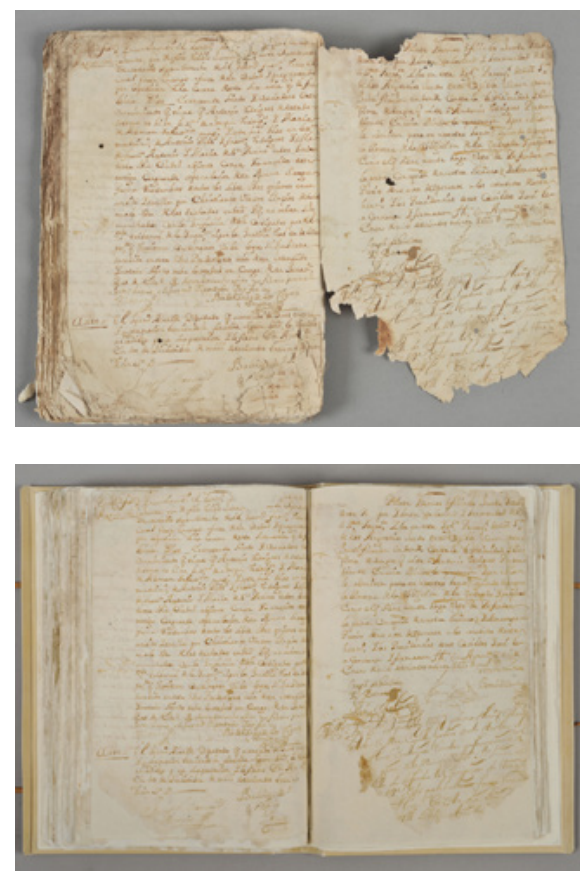

Expediente de Limpieza de Sangre. Ayamonte. Estado inicial (arrriba) y final (debajo) | foto Fondo Gráfico IAPH (Eugenio Fernández Ruiz) 
cativo aprecio social. Está incluida en el Inventario General de bienes Muebles del Patrimonio Histórico Español, según lo dispuesto en la Ley 14/2007 de 26 de noviembre de Patrimonio Histórico de Andalucía, disposición adicional sexta.

\section{Expedientes de Limpieza de Sangre en Ayamonte}

El IAPH restauró en 2010 dos interesantes volúmenes propiedad de la Cofradía Sacramental de las Angustias, cedidos en calidad de depósito permanente al Archivo Municipal de Ayamonte.

Se trata de una colección de Expedientes de Legitimidad y Limpieza de Sangre comprendidos entre los años 1725 y 1760, pertenecientes a la entonces cofradía ayamontina del Santo Sacramento de Ayamonte antes de su fusión con la cofradía del Descendimiento.

Aunque este tipo de expedientes constituye un tipo documental difícil de localizar entre los fondos de cofradías y hermandades religiosas, fue una práctica muy extendida entre estos colectivos. La idea de documentar el origen y procedencia de los individuos y su legitimación como "cristianos puros" fue un requisito indispensable para la admisión en cualquier colectivo público religioso, civil o militar en España desde el siglo XV hasta su supresión por Real Orden en 1835.

\section{Un plano de Isla Cristina}

El Archivo Municipal de Isla Cristina conserva una copia del plano general de la población realizado en 1922 , por orden del ayuntamiento isleño, por el entonces ayudante de obras públicas de la Jefatura Provincial de Isla Cristina, Carlos Rubio.

Durante las primeras décadas del siglo $\mathrm{XX}$, surgió el debate sobre el planeamiento urbano y la necesidad de una gestión municipal más eficaz, promoviéndose la ampliación de las competencias municipales para la mejor y más racional gestión urbanística que desembocaría en los nuevos planes urbanísticos encaminados a optimizar el espacio y encauzar racionalmente el crecimiento de las ciudades.
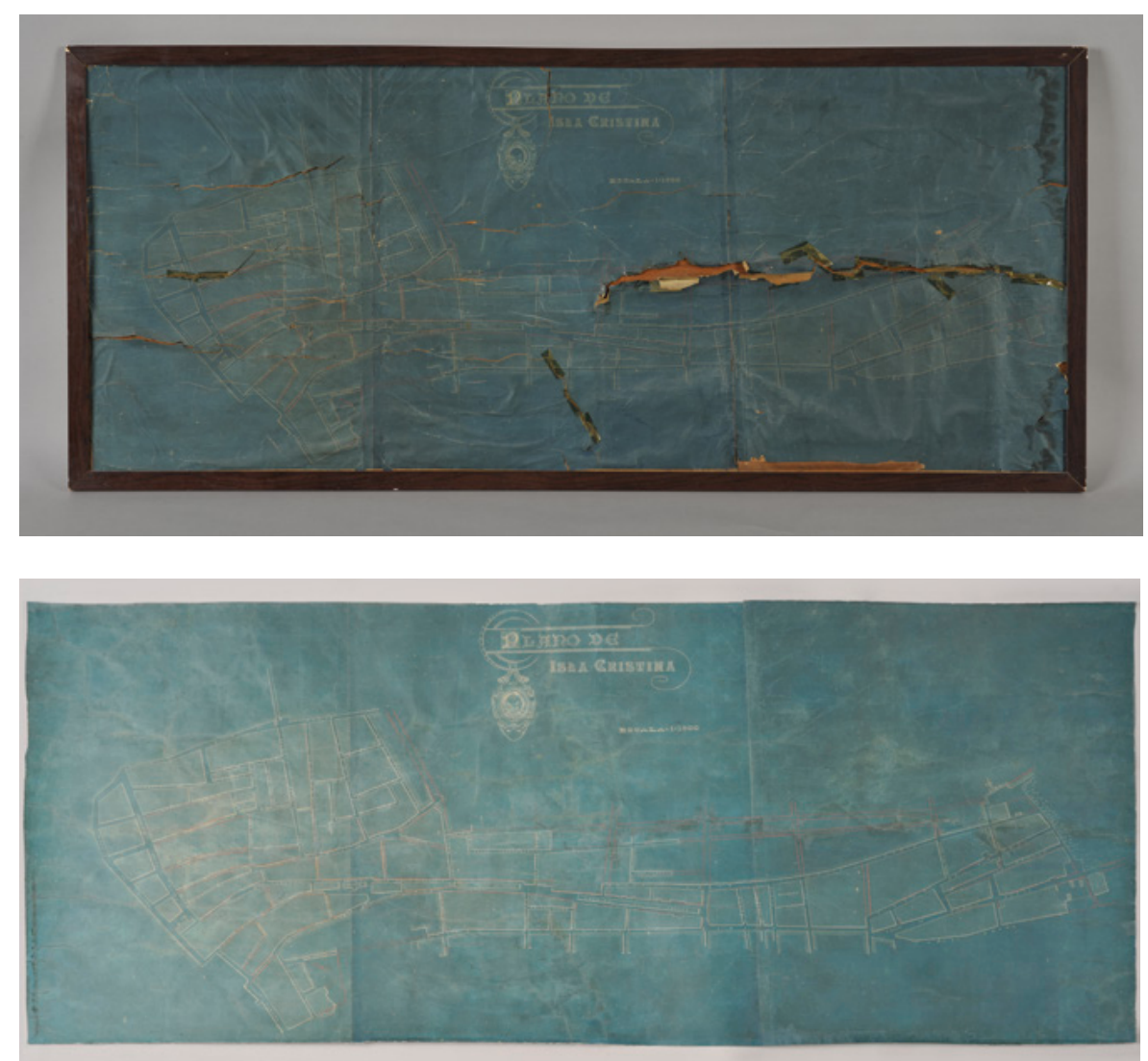

Plano de Isla Cristina. Estado inicial (arriba) y final (debajo) | foto Fondo Gráfico IAPH (Eugenio Fernández Ruiz)
El plano de Isla Cristina, restaurado en el IAPH en 2011, es un ejemplo de estas nuevas políticas. Realizado a escala 1:1000, su particularidad principal es el uso de un papel de fabricación industrial denominado cianotipo o ferroprusiato, que otorga el aspecto de un dibujo en blanco resaltado sobre un fondo azul fuerte.

El uso de este papel se generalizó comercialización en grandes rollos que posibilitaba todo tipo de formatos, fue muy empleado en la reproducción de mapas y planos, hasta su desuso a mediados del siglo XX. hacia 1880, y por su bajo coste y su 